\title{
REVIEW \\ Spinal cord injury and physical activity: preservation of the body
}

\author{
MP Galea
}

Setting: Spinal cord injury (SCl) causes devastating loss of function and can result in serious secondary complications. Although significant advances are being made to develop cellular and molecular therapies to promote regeneration, it is important to optimize physical interventions.

Objectives: The objective of this review was to examine the evidence for the effects of physical rehabilitation strategies on health and fitness, and maintenance of target systems below the level of injury (for example, muscle, bone, circulation).

Results: Exercise appears to be a potent means of achieving these goals, using a variety of strategies.

Conclusion: Physical rehabilitation after $\mathrm{SCI}$ needs to move beyond the goal of maximizing independence to focus on maintenance of optimum health and fitness as well as maintenance of target system function below the level of injury. Issues requiring further investigation include identification of the optimum dosage of interventions to achieve specific goals, for example, prevention of muscle atrophy and osteoporosis, and development and validation of simple clinical measures to monitor the changes in body composition. Adoption of a classification system for physical interventions and standardized outcome measures would facilitate large-scale observational studies to identify the critical variables contributing to better outcomes.

Spinal Cord (2012) 50, 344-351; doi:10.1038/sc.2011.149; published online 13 December 2011

Keywords: human spinal cord injury; rehabilitation; deconditioning; health and fitness

\section{INTRODUCTION}

Rehabilitation after spinal cord injury (SCI) has been based on expectations regarding functional outcomes predicted by the initial level of injury and severity of impairment. ${ }^{1}$ For the most part, rehabilitation has focused on compensatory strategies for identified impairments and deficits that were considered irremediable, because significant recovery of motor function was not expected beyond that predicted by the clinical assessments. ${ }^{2}$ Thus, in patients with clinically complete injuries, therapy has been primarily directed at activities to improve independence, for example, teaching new strategies to move in bed, get dressed, transfer in and out of a wheelchair, as well as provision of assistive devices. In many cases, therapists have had to focus on activities to promote independence in preparation for discharge. $^{2}$ This is reliant on strengthening of muscles above the level of the lesion and using strategies such as leverage, momentum and substitution to move weak or paralyzed parts of the body. Although this approach results in improvements in independent function, it does not promote recovery within central neural circuits for motor control of the paralyzed limbs. A substantial proportion of patients with clinically complete SCI may retain some neuroanatomical continuity or functionally sub-threshold neurophysiological activity across the injury site (discomplete); 3 however, detailed neurophysiological investigations are not routinely used to establish the degree of preserved neural connectivity in individual patients.

In recent years, considerable international effort has been directed to new treatments aimed at repair of the injured spinal cord. Approaches have included limiting secondary cell death, ${ }^{5}$ blocking inhibitory molecules associated with central nervous system (CNS) myelin $^{6}$ or CNS glial scar, ${ }^{7}$ creating a more permissive environment for neural repair, 8,9 including stimulating axonal outgrowth by damaged axons. ${ }^{10}$ Some of these factors are currently being examined in earlystage clinical trials. Given this activity at the level of basic science, it is incumbent on the rehabilitation community to reassess the goals of rehabilitation. Projected functional outcomes for motor complete SCI 12 months post-injury, as described by several studies ${ }^{11,12}$ are currently used to guide rehabilitation goals. Although these are necessary for advising patients and their families, perhaps there needs to be a greater focus on the ongoing maintenance of optimum health and fitness, as well as maintenance of target systems below the level of injury (for example, muscle, bone, circulation) essential for improvement of health outcomes, and for future cures to be realized.

SCI is an extreme example of deconditioning or movement deprivation. The immediate and severe loss of sensory and motor function leads to a period of 'metabolic chaos', wherein extreme systemic catabolism is triggered by the loss of normal physiological stresses to tissue ${ }^{13}$ and neurohumoral responses. ${ }^{14}$ By-products of protein degradation from loss of muscle and bone enter the circulation and increase the demands on the kidneys. Loss of normal muscle forces also contributes to bone demineralization, ${ }^{15}$ which follows a rate of exponential decay. ${ }^{16}$ In addition to cardiovascular and respiratory dysfunction, severe immunosuppression occurs, ${ }^{16,17}$ with patients being vulnerable to infections and their associated inflammatory cascades. Musculoskeletal deterioration, such as fractures and pressure ulcers, as well as systemic infections give rise to serious and costly long-term secondary health complications, which also limit mobility and community integration. 


\section{Objective}

The objective of this review was to examine the evidence for the effects of physical rehabilitation strategies on health and fitness, and maintenance of target systems below the level of injury (for example, muscle, bone, circulation). An additional objective was to highlight areas for future research in this field.

\section{RESULTS}

Physical activity appears to be a potent factor in the maintenance of the health of the person living with SCI, as well as maintaining optimal organ system function. Although many of the issues are interdependent, they will be considered separately below.

\section{Activity and fitness}

People with SCI are considered to be at high risk for an inactive lifestyle, with $40 \%$ of the activity levels of able-bodied peers. ${ }^{18} \mathrm{SCI}$ predisposes to carbohydrate and lipid abnormalities, largely as a consequence of extreme inactivity. ${ }^{19-21}$ People with tetraplegia are at greater risk of disorders of carbohydrate metabolism and those with paraplegia tend to have elevated blood pressure and total cholesterol. ${ }^{22}$ Liang et al..$^{20}$ reported that C-reactive protein levels are higher in men with SCI compared with able-bodied controls, which could also account for the observed decreases in total cholesterol, low-density lipoprotein and high-density lipoprotein. Inactivity can contribute to imbalances in inflammatory response. Skeletal muscles constitute the largest tissue volume in the body. IL-6 is released from contracting muscles in high amounts ${ }^{23}$ and exerts effects on adipose tissue, inducing lipolysis and gene transcription in abdominal subcutaneous fat. ${ }^{24}$ The signaling pathways from contracting muscles to other organs underlying these changes are not neural, as the same physiological changes have been observed in spinal cord-injured individuals. ${ }^{25}$ Furthermore, the release of muscle-derived IL- 6 may reduce TNF- $\alpha$-induced insulin resistance and may therefore be an important mediator of the health benefits from exercise. A recent study ${ }^{26}$ reported that active spinal cord-injured people had lower levels of common risk factors for cardiovascular disease and type 2 diabetes than individuals living with SCI who undertook no leisure-time physical activity.

Regular physical activity through upper-body training has been shown to be effective in improving fitness ${ }^{27}$ and psychological wellbeing in the SCI population. ${ }^{28}$ A number of studies have investigated the role of exercise in improving carbohydrate and lipid metabolism disorders in adults with chronic SCI. Interventions of various frequency and duration have included voluntary exercise and activity stimulated by functional electrical stimulation (FES). The majority of these studies have involved small sample sizes $(n=12-16)$ and were conducted predominantly in males. There is little information as to whether females with SCI respond differently. The benefits of FES are often outweighed by the 'hassle' and time needed to be able to use it. Moreover, such equipment is not readily available, nor suitable for all people with $\mathrm{SCI}^{29} \mathrm{~A}$ recent systematic review concluded that there is insufficient evidence to determine whether exercise improves carbohydrate and lipid metabolism disorders among adults with SCI. ${ }^{30}$

Kehn and $\mathrm{Kroll}^{31}$ highlighted the many barriers to exercise by people with SCI, including: a perceived low return on physical investment, lack of accessible facilities, unaffordable equipment, no personal assistance, and fear of injury. There are examples of local initiatives that encourage regular exercise after SCI, for example, Mac Wheelers program at McMaster University and the Steadward Centre at the University of Alberta, which offer low-cost, supervised exercise facilities in a central location. The Burn Rubber Burn program in
Sydney offers supervised exercise sessions in a number of community fitness centers within and outside the Sydney metropolitan area. The SHAPE study, ${ }^{32}$ a large prospective observational study, has been designed to provide epidemiological information on the determinants and patterns of physical activity and health in people with SCI, as a basis for development of guidelines for physical activity in this population.

Future research in this field could determine an optimal training regimen for improving carbohydrate and lipid metabolism, address methods for accurately measuring the amount and intensity of physical activity, and explore ways to provide low-cost programs to encourage exercise and improvements in the delivery of FES to reduce the burden associated with this intervention (Table 1).

\section{Exercise and circulation}

Following SCI, there is a rapid onset of arterial adaptations, including a $25 \%$ reduction in femoral artery size in parallel with reductions in leg volume, a doubling in blood flow basal shear rate levels, and a significant increase in the flow-mediated dilation response. Flowmediated dilation is a measure of endothelium-related nitric oxide production in response to a shear stress stimulus. These adaptations are established in the superficial femoral artery within 3 weeks postinjury. ${ }^{33}$ Daily FES cycling for 4 weeks reversed these changes in the femoral artery of the exercised limbs. ${ }^{34}$ Non-ambulatory spinal cordinjured individuals have been reported to have increased aortic diameter, abnormal aortic flow patterns, and reduced iliac artery diameter compared with healthy individuals, thus increasing their risk of abdominal aortic aneurysm. ${ }^{35}$ There is an accumulating evidence that repeated episodes of short periods of (lower extremity) exercise (and related increases in arterial wall shear stress) produce sustained cardiovascular benefits that may lower the risk for or progression of abdominal aortic aneurysm disease. ${ }^{36}$ A recent study demonstrated that short bursts of whole-body vibration was an effective method of activating leg muscles and increasing blood flow in people with SCI. ${ }^{37}$

Issues to be addressed in future research could include the effects of lower-limb exercise on aortic and lower extremity arterial flow as well as in the smaller blood vessels (Table 1).

\section{Muscle and body composition}

Consistent with the findings of a multitude of studies on the effects of bed rest, ${ }^{38}$ muscle fiber atrophy occurs quite rapidly after SCI, with significant changes in cross-sectional area apparent within 6 weeks of injury. ${ }^{39}$ Atrophy occurs in type II fibers before type I fibers. ${ }^{40,41}$ Importantly, people with SCI show increased levels of intramuscular fat at 6 weeks post-injury compared with able-bodied controls matched for age, sex, height and weight. Further increases in intramuscular fat occur over the subsequent 3 months. ${ }^{39}$ Transformation of fiber type from type I to type II commences within a few months of injury. In addition, there is a reduction in the proportion of slow myosin heavy chain isoform fibers and an increase in the proportion of fibers co-expressing both fast and slow myosin heavy chain isoforms. The result is that the muscles show less resistance to fatigue. ${ }^{42}$

People with SCI have an average of $5 \mathrm{~kg}$ more fat mass and $50 \%$ more total body fat than able-bodied controls. ${ }^{43}$ In spinal cord-injured people who are sedentary, the levels of body fat are in the 'at risk' category. ${ }^{44}$ Obesity significantly increases the compressive forces on the ischial tuberosities in people with SCI, thus increasing the likelihood of deep tissue injury. ${ }^{45}$ Magnetic resonance imaging or dualenergy X-ray absorptiometry (DEXA) have been used to measure muscle cross-sectional area, intramuscular fat, and fat-tissue mass. 


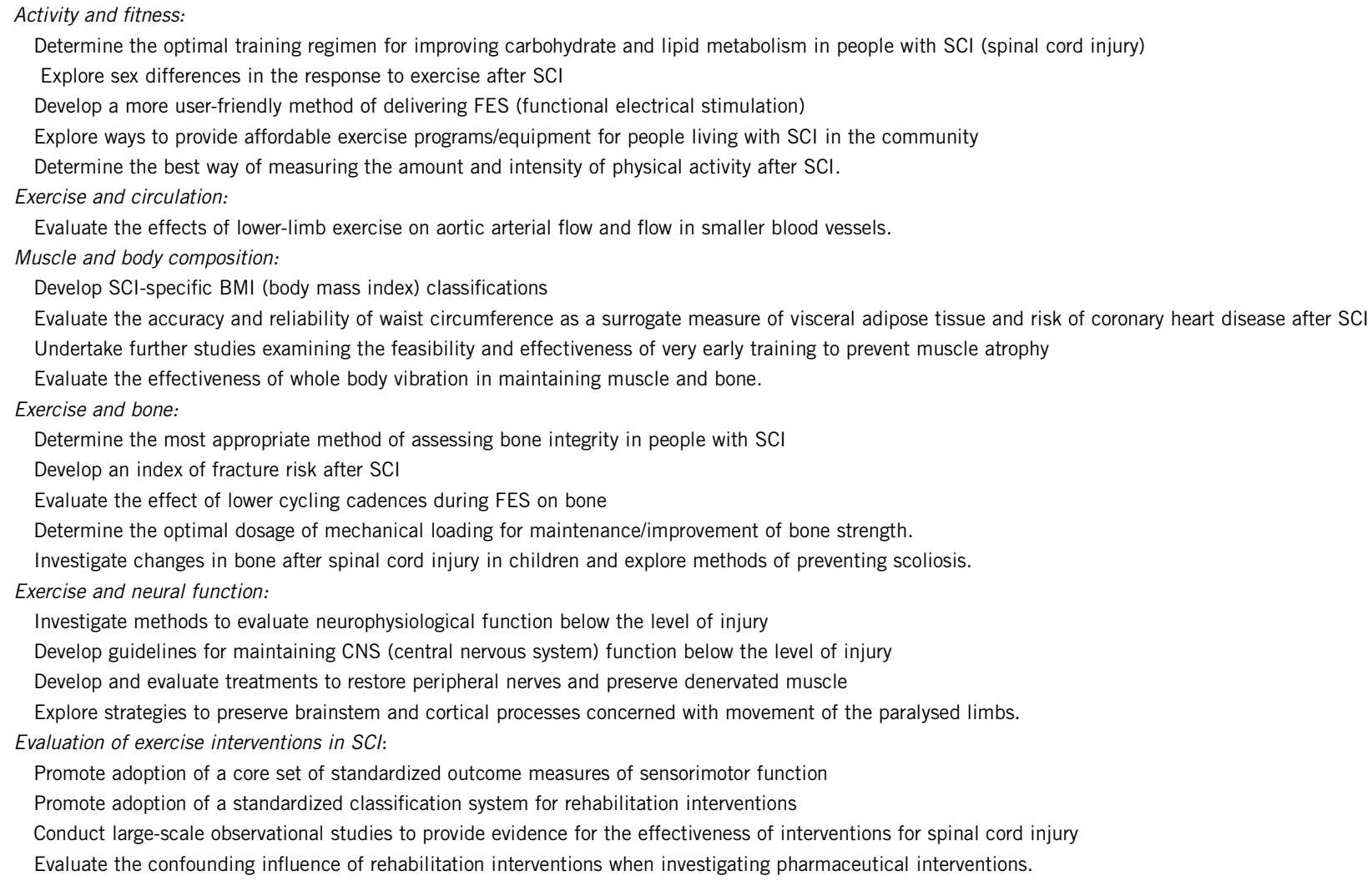

However simpler, less-expensive measures are needed for routine clinical use. BMI and waist circumference measurement are used as markers of obesity and coronary heart disease risk in the able-bodied population. BMI as a surrogate marker of obesity is not sensitive in people with SCI, as body weight measurements do not accurately distinguish between fat mass and fat-free mass. ${ }^{46}$ On the other hand, Laughton et al. ${ }^{47}$ suggested a lower BMI cut-off for obesity in chronic SCI $\left(22 \mathrm{~kg} \mathrm{~m}^{-2}\right.$ rather than $\left.30 \mathrm{~kg} \mathrm{~m}^{-2}\right)$, based on percentage of fat measured using bioelectrical impedance analysis and C-reactive protein. Waist circumference has been shown to be a good surrogate marker of visceral adipose tissue in the able-bodied population. It may be just as useful in people with SCI, subject to determining the most appropriate measurement site, the effects of position (lying, sitting, standing) and the effects of abdominal distension. ${ }^{46}$

The adaptive potential of skeletal muscle in response to use and disuse is well-known, ${ }^{48}$ as are the benefits of regular exercise in reducing the risk of chronic disease, such as cardiovascular disease and diabetes. ${ }^{49}$ Thus, maintaining the activity within paralyzed muscle tissue may provide a means of improving health and well-being of people with SCI. FES provides a means of bypassing the CNS to evoke muscle contractions in the paralyzed limbs and has been used in people with upper motoneuron injuries for many years. ${ }^{50} \mathrm{FES}$-assisted leg exercise has been shown to increase muscle cross-sectional area and to reverse some of the changes in muscle fiber type following SCI. ${ }^{13}$ Critical factors for muscle hypertrophy and fatigue resistance are loading and neuromuscular stimulation frequencies. ${ }^{13}$ Higher pedal torques can be elicited at slower FES cycling cadences. ${ }^{51}$ The potential benefits of training at lower frequencies (for strength training) versus training at higher frequencies (for power training) have yet to be determined. Whole-body vibration exercise, delivered through standing on a vibrating platform, is characterized by cyclic transition between eccentric and concentric muscle contractions, ${ }^{52}$ and may provide another means of exercising the paralysed muscles after SCI. Moreover, the transmission of large muscle forces to the bones in the paralyzed limbs through FES cycling or whole-body vibration may provide the stresses needed to reduce osteoporosis (see next section).

Can muscle atrophy be prevented? Baldi et al. ${ }^{53}$ showed that FES cycling was superior to unloaded FES isometric contractions in preventing muscle atrophy in people with SCI less than 3 months post injury. Shields \& Dudley-Javoroski ${ }^{54}$ instituted a daily unilateral isometric plantarflexion electrical stimulation training protocol within the first 6 weeks of SCI, continuing for 2 years, with the other limb serving as a control. The training protocol was designed to overload the muscle and to provide compressive forces to the distal tibia ( $\sim 1-1.5$ times the body weight). This protocol resulted in significant changes in the trained versus the untrained limb with respect to torque, fatigue index, torque rise time and between-twitch fusion. Importantly, it also resulted in the maintenance of trabecular bonemineral density (BMD) in the trained limbs.

Future research in this area could confirm SCI-specific BMI classifications, and address the accuracy and reliability of waist circumference as a surrogate measure of visceral adipose tissue and coronary heart disease risk after SCI, the optimal training parameters for use of FES to provide adequate musculoskeletal stress, and the feasibility and effectiveness of very early training in prevention of lower-limb muscle atrophy. Whole-body vibration may prove to be a user-friendly means of exercising muscles and requires further investigation in people with SCI (Table 1). 


\section{Exercise and bone}

Biomechanical stress is important for maintaining the structural properties of bone through a negative feedback system. ${ }^{55}$ Muscle forces create the peak forces acting on bone, a relationship summarized by the mechanostat theory, ${ }^{56}$ which predicts that bone mass, strength and size will respond to increasing muscle maximal forces through growth or loading. Unloading through disuse or immobilization will have a negative effect on mass, strength and size of bone. Proper functioning of the mechanostat is dependent on normal functioning of the osteocytes, mechanical usage of the skeleton and the endocrine-metabolic environment. ${ }^{57}$ People with SCI have an increased risk for fractures as a result of mild trauma because of osteoporosis. ${ }^{58}$ Although the loss of bone after SCI has been primarily attributed to disuse atrophy, ${ }^{59}$ lack of activity alone is insufficient to explain the considerable bone loss. The term 'neurogenic osteoporosis' has been used to describe the osteoporosis associated with SCI, as completeness of the lesion seems to override other modifiable risk factors for bone loss. ${ }^{60}$ In addition to activity, mechanisms such as hormonal signaling and inflammatory processes are involved in regulating bone remodeling. ${ }^{61}$ For example, SCI results in acute suppression of the parathyroid hormone-vitamin-D axis, with a reduction in serum parathyroid hormone $e^{62}$ and associated low-normal vitamin-D levels ${ }^{63}$ with subsequent bone loss. ${ }^{60}$ The time course is one of the exponential decay, ${ }^{64}$ with steady state in cortical wall thickness reached at 5-7 years post-injury ${ }^{65}$ Little has been published on bone changes in children with SCI. In addition to the typical bone loss in the lower extremities observed after adult SCI, the growing skeleton in children with SCI is also at risk of scoliosis. ${ }^{66,67}$

The optimal method of determining bone strength in people with SCI is yet to be determined. DEXA appears to be the most widely used method of assessing bone mineral content and BMD, but has the potential to yield systematic measurement inaccuracies as a result of tissue variation after SCI. BMD of the lumbar spine, typically reported to be unchanged after SCI, has been shown to be underestimated using standard posterior-anterior DEXA. ${ }^{68}$ Furthermore, no reference values are available for the sites at which fractures commonly occur in SCI (distal epiphyses of the femur and tibia, the proximal epiphysis of the tibia and the tibial and femoral shafts). Moreover, DEXA does not provide information on bone material and geometric properties. ${ }^{57,64}$

Peripheral quantitative computed tomography has been shown to be highly precise in people with SCI, achieving very low coefficients of variation for bone parameters at the femur and tibia $(\sim 1 \%)$. Peripheral quantitative computed tomography enables the measurement of volumetric densities, thereby allowing the separation between cortical and trabecular bone compartments, as well as the assessment of various bone geometric properties such as the polar bone strengthstrain index that is strongly correlated to bone-breaking force. ${ }^{64}$ Interpretation of fracture risk is difficult without measurement of the trabecular component. Eser et al. ${ }^{64}$ showed that in the epiphyses, bone mass was lost through reduction in BMD, whereas in the shaft, bone mass was lost through reductions in cortical wall thickness by resorption at the endosteal surface.

Whether exercise can prevent osteoporosis or reverse it when established is not clear. Studies of astronauts in micro-gravity environment of space would suggest that activity alone is insufficient to prevent pathological changes in skeletal bone; load-bearing appears to be important. A recent systematic review ${ }^{69}$ has concluded that FES cycling does not improve or maintain bone at the tibial diaphysis in the acute phase, but may increase/maintain lower extremity BMD in the chronic phase after SCI. There is a suggestion of a dose-dependent effect, ${ }^{70}$ and the effects disappear if cycling is not sustained. ${ }^{71}$ The results of two studies investigating the effects of electrical stimulation applied to the quadriceps with the participant in supine during the first few weeks after injury have yielded different results with respect to prevention of bone loss in the femur. ${ }^{72,73}$ Contradictory effects have also been reported for standing training, possibly related to differences in dosage. Ben et al. ${ }^{74}$ showed that standing training performed for half an hour three times per week for 12 weeks appeared to be ineffective in changing bone density in the femur (measured using DEXA) in people who were a mean of 4 weeks post SCI, whereas de Bruin et al. ${ }^{75}$ showed that standing training commenced within the first 4 weeks of injury appeared to ameliorate trabecular bone loss (using CT) over a longer period (25 weeks). Because bone changes have typically been assessed using absorptiometry, it is possible that effects on trabecular bone, which is more likely to respond to loading stimuli, may have been missed, as this method cannot differentiate between cortical and trabecular bone. ${ }^{57}$ Shields and Dudley-Javoroski ${ }^{4}$ have shown that training involving compressive loads delivered to one tibia via electrically stimulated muscle contractions in people with complete spinal injury (ASIA A) resulted in trabecular BMD in the distal tibia, measured using peripheral quantitative computed tomography, that was $30 \%$ higher in the trained compared with the untrained limb.

The magnitude of loading that is effective in attenuating decline in bone density is yet to be determined. Typical FES cycling protocols involve high cycling cadences with the aim of increasing endurance. Fornusek and Davis ${ }^{51}$ have shown that higher muscle forces can be stimulated at lower cycling cadences and suggest that such strength training may have a beneficial effect on bone density. This is yet to be investigated.

Vibration has also been suggested as a potential osteogenic stimulus. The one published study involved application of vibration to the arms and reported no significant effects on bone density, measured using DEXA. ${ }^{76}$

Understanding bone structural strength, decay and remodeling ${ }^{77}$ is the key to better treatments to prevent and treat bone decay in people with SCI. Issues that could be addressed in future research include a recommendation as to the most appropriate method of measuring bone parameters in people with SCI, determination of an index of fracture risk after SCI, whether bone density can be positively affected by using lower cycling cadences during FES, and identification of the optimal dosage of mechanical loading for maintenance or improvement of bone density (Table 1).

\section{Exercise and neural function}

(a) CNS. A substantial proportion of patients with clinically complete SCI may retain some (functionally sub-threshold) neuroanatomical and neurophysiological continuity across the injury site (discomplete). ${ }^{3,4}$ An assumption has been made that spinal circuitry below the level of injury remains largely intact. However, because of the lack of modulation by disrupted descending pathways, many individuals demonstrate abnormal reflexes, which are often pharmacologically suppressed. ${ }^{78}$ Numerous studies in both animals ${ }^{79,80}$ and humans ${ }^{81,82}$ have demonstrated that the spinal cord retains the ability to produce oscillating patterns of activity such as those required for gait. There is now a substantial literature demonstrating the role of activity-dependent plasticity leading to recovery of function after SCI. ${ }^{83,84}$

Sensory information about lower extremity loading provides important cues that modulate the patterns of muscle activity. ${ }^{85}$ Thus, the peripheral nervous system remains a critical component in the modulation of spinal cord activity below the level of injury. 
Studies of motor axons in people at various stages after SCI, however, have shown marked abnormalities in excitability. ${ }^{86,87}$ Deterioration of the peripheral nervous system over time may mean that any future treatments to repair the spinal cord will be ineffective in restoring the function. The Brain Motor Control Assessment ${ }^{88}$ protocol involves comprehensive multi-channel surface EMG recording used to characterize motor responses evoked by voluntary and passive manoeuvers and by reflex responses in people SCI. The overall temporal pattern of motor unit activity reveals features of motor control not apparent in the clinical examination. The Brain Motor Control Assessment may prove useful in assessing motor function below the level of injury and in monitoring the changes in neural function over time.

Furthermore, adaptations occur within the CNS to the changed inputs from the periphery after injury. ${ }^{89} \mathrm{SCI}$ results in a substantial increase of neuronal activation in the ipsilateral dorsal horn, even for non-painful stimuli. ${ }^{90}$ Cortical representations of the spared upper limb enlarge and invade the adjacent sensory-deprived lower-limb territory in the primary somatosensory cortex as early as 3 days after thoracolumbar level injury. ${ }^{91}$ After cervical SCI, shifts have been noted in the representation of tongue movement ${ }^{92}$ and elbow movements. ${ }^{86}$ These observations highlight the interactions between the nervous system, the body and the environment, ${ }^{93}$ and the need to preserve brain function after SCI. ${ }^{94}$

(b) Peripheral nervous system. Lower motoneuron damage after SCI presents a particularly difficult problem, as no recovery of function is possible without an intact peripheral nerve. In the case of nerve root avulsion in humans, reimplantation may lead to useful motor function, ${ }^{95}$ amelioration of pain ${ }^{96}$ and protection of centrally projecting dorsal column pathways. ${ }^{97,98}$

Electrical stimulation has been proposed as a potential intervention to preserve muscle function or to promote regeneration of the damaged peripheral nerve; however, the literature has conflicting reports on this matter. A brief period of electrical stimulation at $20 \mathrm{~Hz}$ to the proximal stump of a damaged peripheral nerve at the time of repair has been shown to promote the speed and accuracy of motor $^{99}$ and sensory ${ }^{100,101}$ nerve regeneration in rats. This is associated with increased expression of BDNF and trkB ${ }^{102}$ and of GAP-43 in the regenerating neurons. ${ }^{101}$ Similar effects on nerve regeneration have been observed after nerve stimulation following median nerve repair at the carpal tunnel in humans. ${ }^{103}$ Critical factors identified from animal studies are: (1) the frequency of stimulation, with higher frequencies leading to less regeneration than lower frequencies ${ }^{104}$ and (2) the timing of application of the stimulation, with a delay of 1-2 weeks resulting in better recovery than immediate application. ${ }^{105}$ Application of stimulation to the denervated muscle in rats has shown conflicting results, with some studies reporting enhanced muscle responses, ${ }^{106}$ and others showing negative and potentially harmful effects. ${ }^{107}$ Hamilton et al. ${ }^{108}$ showed that although electrical stimulation enhanced regeneration of the sciatic nerve in rats, it also increased the number of misdirected axons. There is considerable variation in the stimulation protocols reported in the literature, and a systematic study of the various parameters is needed before a recommendation regarding clinical application can be made.

Exercise, even in short bursts, has also been shown to have positive effects on the regeneration of both motor ${ }^{109}$ and sensory ${ }^{110}$ nerves in rats, mediated by neurotrophic effects. ${ }^{111}$ Asensio-Pinilla et al. ${ }^{112}$ used brief electrical stimulation applied soon after sciatic nerve injury in rats, or moderate intensity treadmill training or a combination of both. Each led to accelerated nerve regeneration and enhanced muscle reinnervation. Electrical stimulation applied for a longer period had no effect. The intensity of exercise is an important consideration, as overwork of a muscle in the early phase of reinnervation has been shown to inhibit recovery in rats. ${ }^{113}$ Other types of stimulation may also affect recovery; for example, sensory stimulation of the paralysed whiskers in rats with facial nerve injury can promote functional recovery of vibrissal movements. ${ }^{114}$

Preservation of muscle properties after denervation would also appear to be a worthy goal, as muscle rapidly loses the ability to become reinnervated. ${ }^{115}$ Electrical stimulation to the denervated muscles preserves muscle bulk and attenuates the strength-related changes associated with denervation in animal studies. ${ }^{116}$ Stimulation needs to be commenced early after injury, and stimulation parameters need to elicit contractions that are similar to normal muscle action. Importantly, to be effective, all denervated muscle fibers need to be stimulated, therefore stimulation parameters need to be carefully selected if surface electrodes are to be used. ${ }^{112}$ In the case of lower extremity muscles, where the distance a peripheral nerve has to regenerate is quite long, electrical stimulation will need to be provided for a long period, but can be feasibly done in humans. ${ }^{117}$

Future cures are critically dependent on preservation of neural function below the level of injury. Therefore, new research should address how nervous system function can be maintained below the level of injury, treatments to restore peripheral nerves and preserve denervated muscle and strategies to preserve brainstem and cortical processes concerned with movement of the paralysed limbs (Table 1).

\section{Evaluation of exercise interventions in SCI}

Recent systematic reviews of rehabilitation interventions for improving lower-limb function ${ }^{118}$ or upper-limb function ${ }^{119}$ after SCI highlight similar issues: the small number of randomized controlled trials (RCT), the relatively small sample sizes in these trials, and the sub-optimal quality of clinical trials in this field. Systematic reviews exclude many studies. Other reviews ${ }^{120,121}$ from SCIRE (Spinal Cord Injury Rehabilitation Evidence) are more inclusive, but the heterogeneity of studies, particularly with respect to the variety of outcome measures used and the different types of intervention, make it difficult to synthesize and use this information to guide clinical practice. Invariably, conclusions are that further research is needed to determine the optimal dosage, and the particular sub-group (injury level, severity, chronicity) that is more likely to benefit from the intervention. Filling the gaps in the evidence base presents major challenges, not the least of which relates to study design. It has been suggested that, given the widespread gaps in evidence-based knowledge, there are systematic flaws in the production of scientific evidence. $^{122}$

The gold-standard of experimental design in clinical research is considered to be the RCT, as observational and non-experimental research designs are susceptible to bias and confounding variables. ${ }^{123}$ Martin Ginis and Hicks ${ }^{124}$ identified a series of methodological, ethical and practical challenges associated with the use of the RCT in assessing the effectiveness of exercise in people with SCI, not the least of which is the heterogeneity of the SCI population. They highlighted the need for a balanced approach to evaluation that accommodates the realities of the SCI population with the need to conduct controlled trials. Berguer, ${ }^{125}$ in a commentary on evidencebased medicine, questioned the tenet of the RCT as the ideal form of clinical research. In recent years, there has been a push for comparative effectiveness research (CER), defined as '...the generation and synthesis of evidence that compares the benefits and harms of alternative methods to prevent, diagnose, treat, and monitor or improve the delivery of care. The purpose of CER is to assist consumers, clinicians, purchasers, and 
policy makers to make informed decisions that will improve health care at both the individual and population levels ${ }^{326}$ (p. S7). Unlike RCTs, which typically address efficacy, effectiveness studies have few exclusion criteria, taking clinical heterogeneity of patient populations, intervention combinations and outcomes into account, thus maximizing the external validity (generalizability and applicability) of a study.

In the context of CER, Horn et al. ${ }^{127}$ have introduced the concept of practice-based evidence as an alternative to RCTs. They challenge the view that observational studies are not sufficient as scientific evidence to effect change in clinical practice. Practice-based evidence studies overcome many of the difficulties associated with RCTs that require meeting conditions for estimation of unbiased effects, notably standardization of treatment protocols, restrictive selection criteria (and therefore generalizability), blinding and randomization. Practicebased evidence studies do not alter a treatment regimen to evaluate the efficacy of a particular intervention, but examine what actually happens as part of standard care. It has the advantage of large numbers of participants, as there are no constraints with respect to selection criteria. Key patient characteristics, all treatment processes and outcomes are gathered into a large study database. Multivariate statistical methods are then used to compare alternative treatments while controlling for other variables that may be driving observed differences between treatments and outcomes.

Such studies require classification of rehabilitation interventions to enable recording of treatment delivered. One system to classify interventions for mobility and self-care has been developed, and shown to be reliable (the SCI-Interventions Classification System $\left.{ }^{128,129}\right)$. Another has been created as part of the SCIRehab project, ${ }^{130}$ a large multi-centre prospective cohort study designed to follow a large number of patients longitudinally to evaluate the impact of rehabilitation interventions on outcome at discharge. This has involved the development of a taxonomy of rehabilitation interventions and agreement on standardized documentation forms. Other initiatives along these lines already exist, notably the European Multicenter Study about Spinal Cord Injury (EMSCI), and the ICF Core Sets ${ }^{131,132}$ also provide a useful framework for determining relevant outcome measures. The difficulties of developing and then rolling out a manageable, multinational data set, especially the workload involved in completing the documentation, cannot be under-estimated. ${ }^{133}$ However, the benefits are potentially substantial.

In order to undertake such studies, there needs to be consensus on, and adoption of a core set of standardized outcome measures and classification of rehabilitation interventions. Then further research can address the confounding influence of rehabilitation interventions when investigating pharmaceutical interventions, and whether largescale observational studies can provide evidence of the effectiveness of interventions for SCI (Table 1).

\section{CONCLUSION}

Physical rehabilitation after SCI needs to move beyond the goal of maximizing independence to focus on maintenance of optimum health and fitness, as well as maintenance of target system function below the level of injury. Exercising the paralysed limbs is a potent means of achieving these objectives. Each of the preceding sections concludes with suggestions for future research. There is a need to determine the optimal training regimens to improve fitness levels. Barriers to exercise, such as a lack of access to suitable facilities and equipment, or the burden associated with using modalities such as FES, need to be addressed. Developing and validating simple measures such as SCI-specific BMI classifications, or waist circumference as a surrogate measure of risk of coronary heart disease would facilitate the monitoring of changes in body composition. There is a need to determine the optimal dosage of interventions to achieve specific goals, for example, prevention of muscle atrophy and osteoporosis and preservation of neural function. Finally, for evaluation of exercise interventions, there is a need for consensus on, and adoption of a classification system for physical interventions and standardized outcome measures. This would facilitate large-scale observational studies to identify the critical variables contributing to better outcomes.

\section{DATA ARCHIVING}

There was no data to deposit.

\section{CONFLICT OF INTEREST}

The author declares no conflict of interest.

1 Kirschblum SC, O'Connor KC. Levels of spinal cord injury and predictors of neurologic recovery. Phys Med Rehabil Clin N Am 2000; 11: 1-27.

2 Behrman AL, Harkema SJ. Physical rehabilitation as an agent for recovery after spinal cord injury. Phys Med Rehabil Clin N Am 2007; 18: 183-202.

3 Dimitrijevic MR, Dimitrijevic MM, Faganel J, Sherwood AM. Suprasegmentally induced motor unit activity in paralyzed muscles of patients with spinal cord injury. Ann Neurol 1984; 16: 216-221.

4 Kakulas BA. A review of the neuropathology of human spinal cord injury with emphasis on special features. J Spinal Cord Med 1999; 22: 119-124.

5 Rowland JW, Hawryluk GW, Kwon B, Fehlings MG. Current status of acute spinal cord injury pathophysiology and emerging therapies: promise on the horizon. Neurosurg Focus 2008; 25: E2.

6 Buchli AD, Schwab ME. Inhibition of Nogo: a key strategy to increase regeneration, plasticity and functional recovery of the lesioned central nervous system. Ann Med 2005; 37: 556-567.

7 Fawcett JW. Overcoming inhibition in the damaged spinal cord. J Neurotrauma 2006; 23: 371-383.

8 Lu P, Yang H, Jones LL, Filbin MT, Tuszynski MH. Combinatorial therapy with neurotrophins and CAMP promotes axonal regeneration beyond sites of spinal cord injury. J Neurosci 2004; 24: 6402-6409.

9 Raisman G. Olfactory ensheathing cells - another miracle cure for spinal cord injury? Nat Rev Neurosci 2001; 2: 369-375.

10 Dergham P, Ellezam B, Essagian C, Avedissian H, Lubell WD, McKerracher L. Rho signaling pathway targeted to promote spinal cord repair. J Neurosci 2002; 22: 6570-6577.

11 Fawcett JW, Curt A, Steeves JD, Coleman WP, Tuszynski MH, Lammertse D et al. Guidelines for the conduct of clinical trials for spinal cord injury (SCI) as developed by the ICCP Panel: spontaneous recovery after spinal cord injury and statistical power needed for therapeutic clinical trials. Spinal Cord 2007; 45: 190-205.

12 Kirshblum SC, Priebe MM, Ho CH, Scelza WM, Chiod AE, Wuermser L-A. Spinal cord injury medicine. 3. Rehabilitation phase after acute spinal cord injury. Arch Phys Med Rehabil 2007; 88: S62-S70.

13 Dudley-Javoroski S, Shields RK. Muscle and bone plasticity after spinal cord injury: Review of adaptations to disuse and to electrical stimulation. J Rehabil Res Dev2008; 45: 283-296.

14 Fredrickson MD. Acute spinal cord injury management. J Trauma 2007; 62: S9.

15 Wilmet E, Ismail AA, Heilporn A, Welraeds D, Bergmann P. Longitudinal study of the bone mineral content and of soft tissue composition after spinal cord section. Paraplegia 1995; 33: 674-677.

16 Eser $\mathrm{P}$, Schiessl H, Willnecker J. Bone loss and steady state after spinal cord injury: a cross-sectional study using pQCT. J Musculoskelet Neuronal Interact 2004; 4: 197-198.

17 Elenkov IJ. Neurohormonal-cytokine interactions: implications for inflammation, common human diseases and well-being. Neurochem Int 2008; 52: 40-51.

18 Van den Berg-Emons RJ, Bussmann JB, Stam HJ. Accelerometry-based activity spectrum in persons with chronic physical conditions. Arch Phys Med Rehabil 2010; 91: 1856-1861.

19 Bauman WA, Spungen AM. Disorders of carbohydrate and lipid metabolism in veterans with paraplegia or quadriplegia: a model of premature aging. Metabolism 1994; 43: 749-756.

20 Liang $H$, Chen $D$, Wang $Y$, Rimmer JH, Braunschwieg CL. Different risk factor patters for metabolic syndrome in men with spinal cord injury compared with ablebodied men despite similar prevalence rates. Arch Phys Med Rehabil 2007; 88: 1198-1204.

21 Hitzig SL, Eng JJ, Miller WC, Sakakibara BM. An evidence-based review of ageing of the body systems following spinal cord injury. Spinal Cord 2010; 49: 684-701. 
22 Groah SL, Nash MS, Ward EA, Libin A, Mendez AJ, Burns P et al. Cardiometabolic risk in community-dwelling persons with chronic spinal cord injury. J Cardiopulm Rehabil Prev 2011; 31: 73-80.

23 Bruunsgaard $\mathrm{H}$. Physical activity and modulation of systemic low-level inflammation. J Leukoc Biol 2005; 78: 819-835.

24 Pedersen BK, Steensberg A, Fischer C, Keller C, Plomgaard P, Febbraio M et al. Searching for the exercise factor: is IL-6 a candidate? J Musc Res Cell Motil 2003; 24: 113-119.

25 Kjaer M, Pollack SF, Mohr T, Weiss H, Gleim GW, Bach FW et al. Regulation of glucose turnover and hormonal responses during electrical cycling in tetraplegic humans. Am J Physiol (Regulatory Integrative Comp Physiol) 1996; 271: R191-R199.

26 Buchholz AC, Martin Ginis KA, Bray SR, Craven BC, Hicks AL, Hayes KC et al. Greater daily leisure time physical activity is associated with lower chronic disease risk in adults with spinal cord injury. Appl Physiol Nutr Metab 2009; 34: 640-647.

27 Jacobs PL, Nash MS, Rusinowski JW. Circuit training provides cardiorespiratory and strength benefits in persons with paraplegia. Med Sci Sports Exerc 2001; 33: 711-717.

28 Hicks AL, Martin KA, Ditor DS, Latimer AE, Craven C, Bucharesti J et al. Long-term exercise training in persons with spinal cord injury: effects on strength, arm ergometry performance and psychological well-being. Spinal Cord 2003; 41: 34-43.

29 Donovan-Hall MK, Burridge J, Dibb B, Ellis-Hill C, Rushton D. The views of people with spinal cord injury about the use of functional electrical stimulation. Artif Organs 2011; 35: 204-211.

30 Carlson KF, Wilt TJ, Taylor BC, Goldish GD, Niewoehner CB, Shamliyan TA et al. Effect of exercise on disorders of carbohydrate and lipid metabolism in adults with traumatic spinal cord injury: systematic review of the evidence. J Spinal Cord Med 2009; 32: 361-378.

31 Kehn M, Kroll T. Staying physically active after spinal cord injury: a qualitative exploration of barriers and facilitators to exercise participation. BMC Public Health 2009; 9: 168.

32 Martin Ginis KA, Latimer AE, Buchholz AC, Bray SR, Craven BC, Hayes KC et al. Establishing evidence-based physical activity guidelines: methods for the Study of Health and Physical Activity in People with Spinal Cord Injury (SHAPE SCI). Spinal Cord 2008; 46: 216-221.

33 De Groot P, Bleeker MW, van Kuppevelt DH, van der Woude LH, Hopman MT. Rapid and extensive arterial adaptations after spinal cord injury. Arch Phys Med Rehabil 2006; 87: 688-696.

34 De Groot P, Crozier J, Rakobowchuk M, Hopman M, MacDonald M. Electrical stimulation alters FMD and arterial compliance in extremely inactive legs. Med Sci Sports Exerc 2005; 37: 1356-1364.

35 Yeung JJ, Kim HJ, Abbruzzese TA, Vignon-Clementel IE, Draney-Blomme MT, Yeung $\mathrm{KK}$ et al. Aortoiliac hemodynamic and morphologic adaptation to chronic spinal cord injury. J Vasc Surg 2006; 44: 1254-1265.

36 Bassuk SS, Manson JE. Physical activity and the prevention of cardiovascular disease. Curr Atheroscler Rep 2003; 5: 299-307.

37 Herrero AJ, Menendez H, Gil L, Martin J, Martin T, Garcia-Lopez D et al. Effects of whole body vibration on blood flow and neuromuscular activity in spinal cord injury. Spinal Cord 2010; 49: 554-559.

38 Convertino VA, Bloomfield SA, Greenleaf JE. An overview of the issues: physiological effects of bed rest and restricted physical activity. Med Sci Sports Exerc 1997; 29: 187-190.

39 Gorgey AS, Dudley GA. Skeletal muscle atrophy and increased intramuscular fat after incomplete spinal cord injury. Spinal Cord 2007; 45: 304-309.

40 Lotta S, Scelsi R, Alfonsi E, Saitta A, Nicolotti D, Epifani P et al. Morphometric and neurophysiological analysis of skeletal muscle in paraplegic patients with traumatic cord lesion. Paraplegia 1991; 29: 247-252.

41 Scelsi R, Marchetti C, Poggi P, Lotta S, Lommi G. Muscle fiber type morphology and distribution in paraplegic patients with traumatic cord lesion. Histochemical and ultrastructural aspects of rectus femoris muscle. Acta Neuropathol 1982; 57: 243-248.

42 Biering-Sørensen B, Bruun Kristensen I, Kjaer M, Biering-Sørensen F. Muscle after spinal cord injury. Muscle Nerve 2009; 40: 499-519.

43 Spungen AM, Adkins RH, Stewart CA, Wang J, Pierson RN, Waters RL et al. Factors influencing body composition in persons with spinal cord injury: across-sectional study. J Appl Physiol 2003; 95: 2398-2407.

44 Kocina P. Body composition of spinal cord injured adults. Sports Med 1997; 23 : 48-60.

45 Elsner JJ, Gefen A. Is obesity a risk factor for deep tissue injury in patients with spinal cord injury? J Biomech 2008; 41: 3322-3331.

46 Buchholz AC, Bucharesti JM. A review of body mass index and waist circumference as markers of obesity and coronary heart disease risk in persons with chronic spinal cord injury. Spinal Cord 2005; 43: 513-518.

47 Laughton GE, Buchholz AC, Martin Ginis KA, Goy RE. Lowering body mass index cutoffs better identifies obese persons with spinal cord injury. Spinal Cord 2009; 47: 757-762.

48 Rose SJ, Rothstein JM. Muscle mutability. Part I. General concepts and adaptations to altered patterns of use. Phys Ther 1982; 62: 1773-1787.

49 Dishman RK, Berthoud H-R, Booth FW, Cotman CW, Edgerton VR, Fleschner MR et al. Neurobiology of exercise. Obesity 2006; 14: 345-356.

50 Sheffler LR, Chae J. Neuromuscular electrical stimulation in neurorehabilitation. Muscle Nerve 2007; 35: 562-590.

51 Fornusek C, Davis GM. Maximizing muscle force via low cadence functional electrical stimulation cycling. J Rehabil Med 2004; 36: 232-237.
52 Rittweger J. Vibration as an exercise modality: how may it work, and what its potential might be. Eur J Appl Physiol 2010; 108: 877-904.

53 Baldi JC, Jackson RD, Moraille R, Mysiw WJ. Muscle atrophy is prevented in patients with acute spinal cord injury using functional electrical stimulation. Spinal Cord 1998; 36: 463-469.

54 Shields RK, Dudley-Javoroski S. Musculoskeletal plasticity after acute spinal cord injury: effects of long-term neuromuscular electrical stimulation training. J Neurophysiol 2006; 95: 2380-2390.

55 Lanyon LE. Osteocytes, strain detection, bone modeling and remodeling. Calcif Tissue Int 1993; 53: S102-S106.

56 Frost HM. Bone's mechanostat: a 2003 update. Anat Rec Pt A 2003; 275A: 1081-1101.

57 Cointry GR, Capozza RF, Negri AL, Roldan EJA, Ferretti JL. Biomechanical background for a non-invasive assessment of bone strength and muscle-bone interactions. J Musculoskel Neuron Interact 2004; 4: 1-11.

58 Ragnarsson KT, Sell GH. Lower extremity fractures after spinal cord injury: a retrospective study. Arch Phys Med Rehabil 1981; 62: 418-423.

59 Jones PR, Pearson J. Anthropometric determination of leg fat and muscle plus bone volumes in young male and female adults. J Physiol 1969; 204: 63P-66P.

60 Garland DE, Adkins RH, Kushawa V, Stewart C. Risk factors for osteoporosis at the knee in the spinal cord injury population. J Spinal Cord Med 2004; 27: 202-206.

61 Jiang S-D, Jiang L-S, Dai L-Y. Mechanisms of osteoporosis in spinal cord injury. Clin Endocrinol 2006; 65: 555-565.

62 Riegger T, Conrad S, Liu K, Schluesener HJ, Adibzahdeh M, Schwab JM. Spinal cord injury-induced immune depression syndrome (SCI-IDS). Eur J Neurosci 2007; 25: 1743-1747.

63 Bauman WA, Zhong YG, Schwartz E. Vitamin D deficiency in veterans with chronic spinal cord injury. Metabolism 1995; 44: 1612-1616.

64 Eser P, Frotzler A, Zehnder Y, Wick L, Knecht H, Denoth J et al. Relationship between the duration of paralysis and bone structure: a pQCT study of spinal cord-injured individuals. Bone 2004; 34: 869-880.

65 Eser P, Frotzler A, Zehnder Y, Denoth J. Fracture threshold in the femur and tibia of people with spinal cord injury as determined by peripheral quantitative computed tomography. Arch Phys Med Rehabil 2005; 86: 498-504.

66 Kannisto M, Alaranta H, Merikanto J, Kröger H, Kärkkäinen J. Bone mineral status after pediatric spinal cord injury. Spinal Cord 1998; 36: 641-646.

67 Bergström EM, Short DJ, Frankel HL, Henderson NJ, Jones PR. The effect of childhood spinal cord injury on skeletal development: a retrospective study. Spinal Cord 1999; 37: 838-846.

68 Bauman WA, Kirshblum S, Cirnigliaro C, Forrest GF, Spungen AM. Underestimation of bone loss of the spine with posterior-anterior dual-energy X-ray absorptiometry in patients with spinal cord injury. J Spinal Cord Med 2010; 33: 214-220.

69 Ashe MC, Craven C, Krassioukov A, Eng JJ. Bone health following spinal cord injury. In: Eng JJ, Teasell RW, Miller WC, Wolfe DL, Townson AF, Hsieh JTC, et al. (eds). Spinal Cord Injury Rehabilitation Evidence, Version 3.0. Vancouver, BC: ICORD, 2010, pp 1-29.

70 Frotzler A, Coupaud S, Perret C, Kakebeeke TH, Hunt KJ, Donaldson N deN et al. High-volume Fes-cycling partially reverses bone loss in people with chronic spinal cord injury. Bone 2008; 43: 169-176.

71 Clark JM, Jelbart M, Rischbieth H, Stayer J, Chatterton B, Schulz C et al. Physiological effects of lower extremity functional electrical stimulation in early spinal cord injury: lack of efficacy to prevent bone loss. Spinal Cord 2007; 45: 78-85.

72 Groah SL, Lichy AM, Libin AV, Ljungberg I. Intensive electrical stimulation attenuates femoral bone loss in acute spinal cord injury. $P M \& R$ 2010; 2: 1080-1087.

73 Mohr T, Pødenphant J, Biering-Sørensen F, Galbo H, Thamsborg G, Kjaer M. Increased bone mineral density after prolonged electrically induced cycle training of paralysed limbs in spinal cord injured man. Calcif Tissue Int 1997; 61: 22-25.

74 Ben M, Harvey L, Denis S, Glinsky J, Goehl G, Chee S et al. Does 12 weeks of regular standing prevent loss of ankle mobility and bone mineral density in people with recent spinal cord injuries? Aust J Physiother 2005; 51: 251-256.

75 de Bruin ED, Frey-Rindova P, Herzog RE, Dietz V, Dambacher MA, Stüssi E. Changes in tibia bone properties after spinal cord injury: effects of early intervention. Arch Phys Med Rehabil 1999; 80: 214-220.

76 Melchiorri G, Andreoli A, Padua E, Sorge R, De Lorenzo A. Use of vibration exercise in spinal cord injury patients who regularly practise sport. Funct Neurol 2007; 22: $151-154$

77 Szulc P, Seeman E. Thinking inside and outside the envelopes of bone. Osteoporos Int 2009; 20: 1281-1288.

78 Kirschblum SC, Priebe MM, Ho CH, Scelza WM, Chiodo AE, Wuermsner L-A. Spinal cord injury medicine. 3. Rehabilitation phase after acute injury. Arch Phys Med Rehabil 2007; 88: S62-S70.

79 Barbeau H, Rossignol S. Recovery of locomotion after chronic spinalization in the adult cat. Brain Res 1987; 412: 84-95.

80 Lovely RG, Gregor RJ, Roy RR, Edgerton VR. Effects of training on the recovery of fullweight-bearing stepping in the adult spinal cat. Exp Neurol 1986; 92: 421-435.

81 Dietz V, Colombo G, Jensen L, Baumgartner L. Locomotor bearing hindlimb stepping in treadmill-exercised adult spinal cats. Ann Neurol 1995; 37: 574-586.

82 Dobkin B, Harkema S, Requejo PS, Edgerton VR. Modulation of locomotor-like EMG activity in subjects with complete and incomplete spinal cord injury. J Neurol Rehabil 1995; 9: 183-190

83 Dunlop SA. Activity-dependent plasticity: implications for recovery after spinal cord injury. Trends Neurosci 2008; 31: 410-418. 
84 Fouad K, Krajacic A, Tetzlaff W. Spinal cord injury and plasticity: opportunities and challenges. Brain Res Bull 2010; 84: 337-342.

85 Harkema SJ, Hurley SL, Patel UK, Requejo PS, Dobkin BH, Edgerton VR. Human lumbosacral spinal cord interprets loading during stepping. J Neurophysiol 1997; 77: 797-811.

86 Lotze M, Laubis-Herrmann U, Topka H. Combination of TMS and fMRI reveals a specific pattern of reorganization in patients after complete spinal cord injury. Restor Neurol Neurosci 2006; 24: 97-107.

87 Lin CS-Y, Macefield VG, Elam M, Wallin BG, Engel S, Kiernan MC. Axonal changes in spinal cord injured patients distal to the site of injury. Brain 2007; 130: 985-994.

88 McKay WB, Ovechkin AV, Vitaz TW, Terson de Paleville DG, Harkema SJ. Neurophysiological characterization of motor recovery in acute spinal cord injury. Spinal Cord 2011; 49: 421-429.

89 Wolpaw JR, Tennissen AM. Activity-dependent spinal cord plasticity in health and disease. Annu Rev Neurosci 2001; 24: 807-843.

90 Endo T, Spenger C, Westman E, Tominaga T, Olson L. Reorganization of sensory processing below the level of spinal cord injury as revealed by fMRI. Exp Neurol 2008; 209: 155-160.

91 Endo T, Spenger C, Westman E, Tominaga T, Olson L. Cortical sensory map rearrangement after spinal cord injury: fMRI responses linked to Nogo signaling. Brain 2007; 130: 2951-2961.

92 Mikulis DJ, Jurkiewicz MT, Mcllroy WE, Staines WR, Rickards L, Kalsi-Ryan S et al. Adaptation in the motor cortex following cervical spinal cord injury. Neurology 2002; 58: 794-801.

93 Chiel HJ, Beer RD. The brain has a body: adaptive behaviour emerges from interactions of nervous system, body and environment. Trends Neurosci 1997; 20: 553-557.

94 Cramer SC, Lastra L, Lacourse MG, Cohen MJ. Brain motor system function after chronic complete spinal cord injury. Brain 2005; 128: 2941-2950.

95 Carlstedt T, Hultgren T, Nyman T, Hansson T. Cortical activity and hand function restoration in a patient after spinal cord surgery. Nat Rev Neurol 2009; 5: 571-574.

96 Carlstedt T, Anand P, Hallin R, Misra PV, Noren G, Seferlis T. Spinal nerve root repair and reimplantation of avulsed ventral roots into the spinal cord after brachial plexus injury. J Neurosurg (Spine) 2000; 93: 237-247.

97 Bigbee AJ, Hoang TX, Havton LA. Reimplantation of avulsed lumbosacral ventral roots in the rat ameliorates injury-induced degeneration of primary afferent axon collaterals in the spinal dorsal columns. Neurosci 2008; 152: 338-345.

98 Havton LA, Carlstedt T. Repair and rehabilitation of plexus and root avulsions in animal models and patients. Curr Opin Neurol 2009; 22: 570-574.

99 Al-Majed AA, Neumann CM, Brushart TM, Gordon T. Brief electrical stimulation promotes the speed and accuracy of motor axonal regeneration. J Neurosci 2000; 20 : 2602-2608.

100 Brushart TM, Jari R, Verge V, Rohde C, Gordon T. Electrical stimulation restores the specificity of sensory axon regeneration. Exp Neurol 2005; 194: 221-229.

101 Geremia NM, Gordon T, Brushart TM, Al-Majed AA, Verge VMK. Electrical stimulation promotes sensory neuron regeneration and growth-associated gene expression. Exp Neurol 2007; 205: 347-359.

102 Al-Majed AA, Brushart TM, Gordon T. Electrical stimulation accelerates and increases expression of BDNF and trkB mRNA in regenerating rat femoral motoneurons. Eur $\mathrm{J}$ Neurosci 2000; 12: 4381-4390.

103 Gordon T, Brushart TM, Chan KM. Augmenting nerve regeneration with electrical stimulation. Neurol Res 2008; 30: 1012-1022.

104 Lu M-C, Ho C-Y, Hsu S-F, Lee H-C, Lin J-H, Yao C-H et al. Effects of electrical stimulation at different frequencies on regeneration of transected peripheral nerve. Neurorehabil Neural Repair 2008; 22: 367-373.

105 Yeh C-C, Lin Y-C, Tsai F-J, Huang C-Y, Yao C-H, Chen Y-S. Timing of applying electrical stimulation is an important factor in deciding the success rate and maturity of regenerating rat sciatic nerves. Neurorehabil Neural Repair 2010; 24 730-735.

106 Marqueste T, Decherchi P, Dousset E, Berthelin F. Effect of muscle electrostimulation on afferent activities from tibialis anterior muscle after nerve repair by self-anastomosis. Neurosci 2002; 13: 257-271.

107 Gigo-Benato D, Russo TL, Geuna S, Domingues NRSR, Salvini TF, Parizotto NA. Electrical stimulation impairs early functional recovery and accentuates skeleta muscle atrophy after sciatic nerve crush injury in rats. Muscle Nerve 2010; 41: 685-693.

108 Hamilton SK, Hinkle ML, Nicolini J, Rambo LN, Rexwinkle AM, Rose SJ et al. Misdirection of regenerating axons and functional recovery following sciatic nerve injury in rats. J Comp Neurol 2011; 519: 21-33.

109 Sabatier MJ, Redmon N, Schwatrz G, English AW. Treadmill training promotes axonal regeneration in injured peripheral nerves. Exp Neurol 2008; 211: 489-493.
110 Molteni R, Zheng J-Q, Ying Z, Gomez-Pinilla F, Twiss JL. Voluntary exercise increases axonal regeneration from sensory neurons. PNAS 2004; 101: 8473-8478.

111 Gomez-Pinilla F, Ying Z, Roy RR, Edgerton VR. Differential regulation by exercise of BDNF and NT-3 in rat spinal cord and skeletal muscle. Eur J Neurosci 2001; 13: 1078-1084.

112 Asensio-Pinilla E, Udina E, Jamarillo J, Navarro X. Electrical stimulation combined with exercise increase axonal regeneration after peripheral nerve injury. Exp Neurol 2009; 219: 258-265.

113 Herbison GJ, Jaweed MM, Ditunno JF. Effect of swimming on reinnervation of rat skeletal muscle. J Neurol Neurosurg Psychiatr 1974; 37: 1247-1251.

114 Angelov DN, Ceynowa M, Guntinas-Lichius O, Streppel M, Grosheva M, Kiryakova SI et al. Mechanical stimulation of paralysed vibrissal muscles following facial nerve injury in adult rat promotes full recovery of whisking. Neurobiol Dis 2007; 26: 229-242.

115 Finkelstein DI, Dooley PC, Luff AR. Recovery of muscle after different periods of denervation and treatments. Muscle Nerve 1993; 16: 769-777.

116 Eberstein A, Eberstein S. Electrical stimulation of denervated muscle: is it worthwhile? Med Sci Sports Exerc 1996; 28: 1463-1469.

117 Kern H, Carraro U, Adami N, Biral D, Hofer C, Forstner C et al. Home-based functional electrical stimulation rescues permanently denervated muscles in paraplegic patients with complete lower motor neuron injury. Neurorehabil Neural Repair 2010; 24: 709-721.

118 Wessels M, Lucas C, Eriks I, de Groot S. Body weight-supported gait training for restoration of walking in people with incomplete spinal cord injury: a systematic review. J Rehabil Med 2010; 42: 513-519.

119 Kloosterman MGM, Snoek GJ, Jannink MJA. Systematic review of the effects of exercise therapy on the upper extremity of patients with spinal cord injury. Spinal Cord 2008; 47: 196-203.

120 Lam T, Wolfe DL, Eng JJ, Domingo A. Lower limb rehabilitation following spinal cord injury. In: Eng JJ, Teasell RW, Miller WC, Wolfe DL, Townson AF, Hsieh JTC, et al. (eds). Spinal Cord Injury Rehabilitation Evidence, Version 3.0. Vancouver, BC: ICORD, 2010, pp 1-47.

121 Connolly S, Mehta S, Foulon B, Teasell RW, Aubut JL. Upper limb rehabilitation following spinal cord injury. In: Eng JJ, Teasell RW, Miller WC, Wolfe DL, Townson AF, Hsieh JTC, et al. (eds). Spinal Cord Injury Rehabilitation Evidence, Version 3.0. Vancouver, BC: ICORD, 2010, pp 1-19.

122 Tunis SR, Stryer DB, Clancy CM. Practical clinical trials. Increasing the value of clinical research for decision-making in clinical and health policy. JAMA 2003; 290: 1624-1632.

123 Lammertse D, Tuszynski MH, Steeves JD, Curt A, Fawcett JW, Rask C et al. Guidelines for the conduct of clinical trials for spinal cord injury (SCI) as developed by the ICCP Panel: clinical trial design. Spinal Cord 2007; 45: 232-242.

124 Martin Ginis KA, Hicks AL. Exercise research issues in the spinal cord injured population. Exerc Sport Sci Rev 2005; 33: 49-53.

125 Berguer R. The evidence thing. Ann Vasc Surg 2004; 18: 265-270.

126 Sox HC. Defining comparative effectiveness research. The importance of getting it right. Med Care 2010; 48: S7-S8.

127 Horn SD, Gassaway J, Pentz L, James RJ. Practice-based evidence for clinical practice improvement: an alternative study design for evidence-based medicine. In: Hovenga EJS, Kidd MR, Garde S, Hullin Lucay Cossio C (eds). Health Informatics, 2nd edn. Amsterdam: IOS Press, 2010, pp 446-460.

128 van Langeveld SA, Post MW, van Asbeck FW, Postma K, ten Dam D, Pons K. Development of a classification of physical, occupational and sports therapy interventions to document mobility and self-care in spinal cord injury rehabilitation. JNPT 2008; 32: 2-7.

129 van Langeveld SA, Post MW, van Asbeck FW, ter Horst P, Leenders J, Postma K et al. Reliability of a new classification system for mobility and self-care in spinal cord injury rehabilitation: the spinal cord injury-interventions classification system. Arch Phys Med Rehabil 2009; 90: 1229-1236.

130 Whiteneck G, Gassaway J. SCIRehab: a model for rehabilitation research using comprehensive person, process and outcome data. Disabil Rehabil 2010; 32: 1035-1042.

131 Cieza A, Kirchberger I, Biering-Sørensen F, Baumberger M, Charlifue S, Post MW et al. ICF Core Sets for individuals with spinal cord injury in the long-term context. Spinal Cord 2010; 48: 305-312.

132 Kirchberger I, Cieza A, Biering-Sørensen F, Baumberger M, Charlifue S, Post MW et al. ICF Core Sets for individuals with spinal cord injury in the early post-acute context. Spinal Cord 2010; 48: 297-304.

133 Turner-Stokes L. Evidence for the effectiveness of multi-disciplinary rehabilitation following acquired brain injury: a synthesis of two systematic approaches. J Rehabil Med 2008; 40: 691-701. 